Tropical Journal of Pharmaceutical Research April 2016; 15 (4): 827-831

ISSN: $1596-5996$ (print); 1596-9827 (electronic)

(C) Pharmacotherapy Group, Faculty of Pharmacy, University of Benin, Benin City, 300001 Nigeria.

All rights reserved.

Available online at http://www.tjpr.org

Original Research Article

http://dx.doi.org/10.4314/tjpr.v15i4.23

\title{
Effects of coagulation factors and inflammatory cytokines on development of acute myocardial infarction in patients younger than 60 years
}

\author{
Jun-jie Wang ${ }^{1}$ and Mei-yun Fang ${ }^{2 \star}$ \\ ${ }^{1}$ Department of Cardiology, ${ }^{2}$ Department of Hematology, The First Affiliated Hospital of Dalian Medical University, Dalian \\ 116011, PR China
}

*For correspondence: Email: fangmeiyun2004@163.com; Tel: +86-041183635963-2168

Received: 15 October 2015

Revised accepted: 9 March 2016

\begin{abstract}
Purpose: To investigate the effects of coagulation factors and inflammatory cytokines on acute myocardial infarction (AMI) development in patients younger than 60 years.

Methods: In this study, 60 patients admitted to The First Affiliated Hospital of Dalian Medical University (Dalian, China) with AMI and 30 other subjects matched with the patients for age and ethnicity but without AMI were enrolled. Blood samples were collected from the AMI patients and the control subjects after a 12-h fast. Subsequently, the levels of coagulation factors (F) II (FII), VII (FVII), VIII (FVIII), fibrinogen (Fg) and von Willebrand factor (VWF) in plasma were analyzed by enzyme-linked immunosorbent assay (ELISA). The protein expression levels of these coagulation factors were determined by Western blot analysis. Inflammatory factors including C-reactive protein (CRP), tumor necrosis factor- $\alpha$ (TNF- $\alpha$ ) and interleukin- 6 (IL-6) were also measured by ELISA.

Results: FII, FVII, FVIII, Fg and vWF levels in plasm were significantly higher in AMI patients compared with control subjects $(p<0.01)$. Furthermore, the protein expression levels of FII, FVII, FVIII, Fg and $\checkmark W F$ were also significantly up-regulated in AMI patients compared with those in control subjects. Additionally, no significant difference was observed in CRP between AMI patients and control subjects $(p>0.05)$. However, TNF- $\alpha$ and IL-6 levels in the plasma of AMI patients were significantly higher than those in control subjects $(p<0.05)$.

Conclusion: The results reveal that the pathogenesis of AMI in patients younger than 60 years might be closely related to the high levels of coagulation factors and inflammatory cytokines in the blood.
\end{abstract}

Keywords: Coagulation factor, Inflammatory cytokines, Acute myocardial infarction, C-reactive protein, Tumor necrosis factor-a, Interleukin- 6

Tropical Journal of Pharmaceutical Research is indexed by Science Citation Index (SciSearch), Scopus, International Pharmaceutical Abstract, Chemical Abstracts, Embase, Index Copernicus, EBSCO, African Index Medicus, JournalSeek, Journal Citation Reports/Science Edition, Directory of Open Access Journals (DOAJ), African Journal Online, Bioline International, Open-J-Gate and Pharmacy Abstracts

\section{INTRODUCTION}

Currently, coronary heart disease (CHD) has become one of the leading global threats to human health [1]. Acute myocardial infarction (AMI) is the major clinical complication of CHD and the main cause of mortality in patients [2]. Although great improvements have been achieved in the diagnosis and treatment of AMI, the short- and long-term mortality rates in AMI patients still remain high [3,4]. In addition, the onset age of $\mathrm{AMI}$ is becoming increasingly low $[5,6]$. Therefore, it is of great significance to investigate the pathogenesis of $\mathrm{AMI}$ in patients younger than 60 years.

Epidemiological studies have revealed that some coagulation factors including coagulation factor 
(F) II (FII), VII (FVII), VIII (FVIII), fibrinogen (Fg) and von Willebrand factor (vWF), are closely related to thrombus formation and $\mathrm{CHD}[7,8]$. In addition, the systemic inflammation response has been documented in patients with $\mathrm{AMI}$, and includes the elevation of circulating inflammatory cytokines such as C-reactive protein (CRP), tumor necrosis factor- $\alpha$ (TNF- $\alpha$ ), and interleukin6 (IL-6) $[9,10]$. However, to the best of our knowledge, there are few reports regarding the effects of coagulation factors and inflammatory cytokines on the occurrence and development of AMI in patients younger than 60 years. The present study was aimed to investigate the effects of coagulation factors and inflammatory cytokines on the development of acute myocardial infarction in patients younger than 60 years, findings that would be beneficial for the accurate diagnosis and effective treatment of AMI in the clinic.

\section{EXPERIMENTAL}

\section{Chemicals and reagents}

Human anti-prothrombin (FII), anti-FVII, antiFVIII, anti-Fg and anti-vWF monoclonal antibodies were obtained from Abcam (Cambridge, UK); CRP, TNF- $\alpha$ and IL-6 ELISA kits were purchased from Pierce/Endogen Co. (Rockford, IL, USA). FII, FVII, FVIII, Fg and vWF enzyme-linked immunosorbent assay (ELSA) kits were purchased from Pierce/Endogen Co. (Rockford, IL, USA). All other reagents used in this study were of analytic grade.

\section{Patients and controls}

Sixty patients (39 males and 21 females) admitted to The First Affiliated Hospital of Dalian Medical University (Dalian, China) with a diagnosis of AMI, defined according to the guidelines of the WHO MONICA protocol [11], were studied. A group of 30 control subjects (19 males and 11 females) matched with the patients for age and ethnicity, were also enrolled in the present investigation. No control subject had episodes of cardiovascular disease and none used antihypertensive or lipid-lowering drugs. The characteristics of AMI patients and controls are shown in Table 1, and no obvious difference of the characteristics was observed between the two groups.

Venous blood samples were collected from the patients during hospitalization and the control subjects after a 12-h fast. Subsequently, 3.8 \% sodium citrate solution $(1: 9, \mathrm{v} / \mathrm{v})$ was added to the blood, and the samples were centrifuged
(3000 rpm, $15 \mathrm{~min}$ ). The isolated plasma was snap-frozen and stored at $-80{ }^{\circ} \mathrm{C}$ before measurement. All our experimental protocols were approved by the ethical committee of The First Affiliated Hospital of Dalian Medical University (Ref no. 20120918-h1). All the patients and controls were residents of the region of Dalian and gave their consent to participate in the study.

Table 1: Baseline demographics and disease characteristics of AMI patients and control subjects

\begin{tabular}{lcc}
\hline Variable & Control & AMI \\
\hline Sex (M/F) & $19 / 11$ & $39 / 21$ \\
Body Weight $(\mathrm{kg})$ & $53.73 \pm 4.97$ & $51.85 \pm 6.16$ \\
Age & $54.74 \pm 5.05$ & $52.03 \pm 7.21$ \\
Smoking (\%) & 60 & 51.67 \\
Hypertension (\%) & 46.7 & 50 \\
Diabetes (\%) & 6.7 & 10 \\
TC (mmmol/L) & $3.48 \pm 0.82$ & $3.69 \pm 0.98$ \\
TG (mmmol/L) & $1.82 \pm 0.63$ & $2.08 \pm 0.73$ \\
Blood sugar & $5.21 \pm 1.14$ & $6.03 \pm 1.96$ \\
(mmmol/L) & &
\end{tabular}

\section{Determination of FII, FVII, FVIII, Fg and vWF levels in plasma}

Coagulation factors including FII, FVII, VIII (FVIII), $\mathrm{Fg}$ and VWF in the plasma were analyzed by enzyme linked immunosorbent assay (ELISA) according to the manufacturer's instructions.

\section{Determination of FII, FVII, FVIII, Fg and vWF protein levels}

Total protein samples were separated by sodium dodecyl sulfate/polyacrylamide gel electrophoresis (SDS/PAGE) and then transferred to a polyvinylidene difluoride (PVDF) membrane. The proteins were probed with the appropriate primary antibodies and secondary antibodies conjugated with horseradish peroxidase subsequently. Next, they were visualized using chemiluminescence peroxidase reagents. To normalize the protein loading, $\beta$ actin was used as the internal control.

\section{Determination of CRP, TNF- $\alpha$ and IL- 6 levels in plasma}

Furthermore, inflammatory cytokines including CRP, TNF- $\alpha$ and IL- 6 were also determined by ELISA according to the manufacturer's instructions.

\section{Statistical analysis}

Data are expressed as mean \pm standard deviation (SD). Student's t-test was used to perform statistical analysis of the data. 
Differences were considered statistically significant at $p<0.05$.

\section{RESULTS}

\section{Levels of coagulation factors in plasma}

As seen in Figure 1, the ELISA results indicate that the plasma levels of coagulation factors, including FII, FVII, FVIII, Fg and vWF, were significantly higher in AMI patients than in control subjects $(p<0.01)$. Furthermore, the western blot assay results also revealed protein expression levels of FII, FVII, FVIII, Fg and vWF were up-regulated obviously in AMl patients compared with those in the control subjects (Figure 2).

\section{CRP, TNF- $\alpha$ and IL-6 levels in plasma}

The plasma levels of inflammatory factors including CRP, TNF- $\alpha$ and IL-6 are shown in Figure 3 . Our results showed that there were no significant differences in the release of CRP between AMI patients and the control subjects ( $p$ $>0.05$ ). Interestingly, the TNF- $\alpha$ and IL-6 levels in the plasma of AMI patients were significantly higher than those of control subjects $(p<0.05)$. Our results showed that the release of inflammatory cytokines, including TNF- $\alpha$ and IL6 , is associated with pathogenesis of AMI patients younger than 60 years.
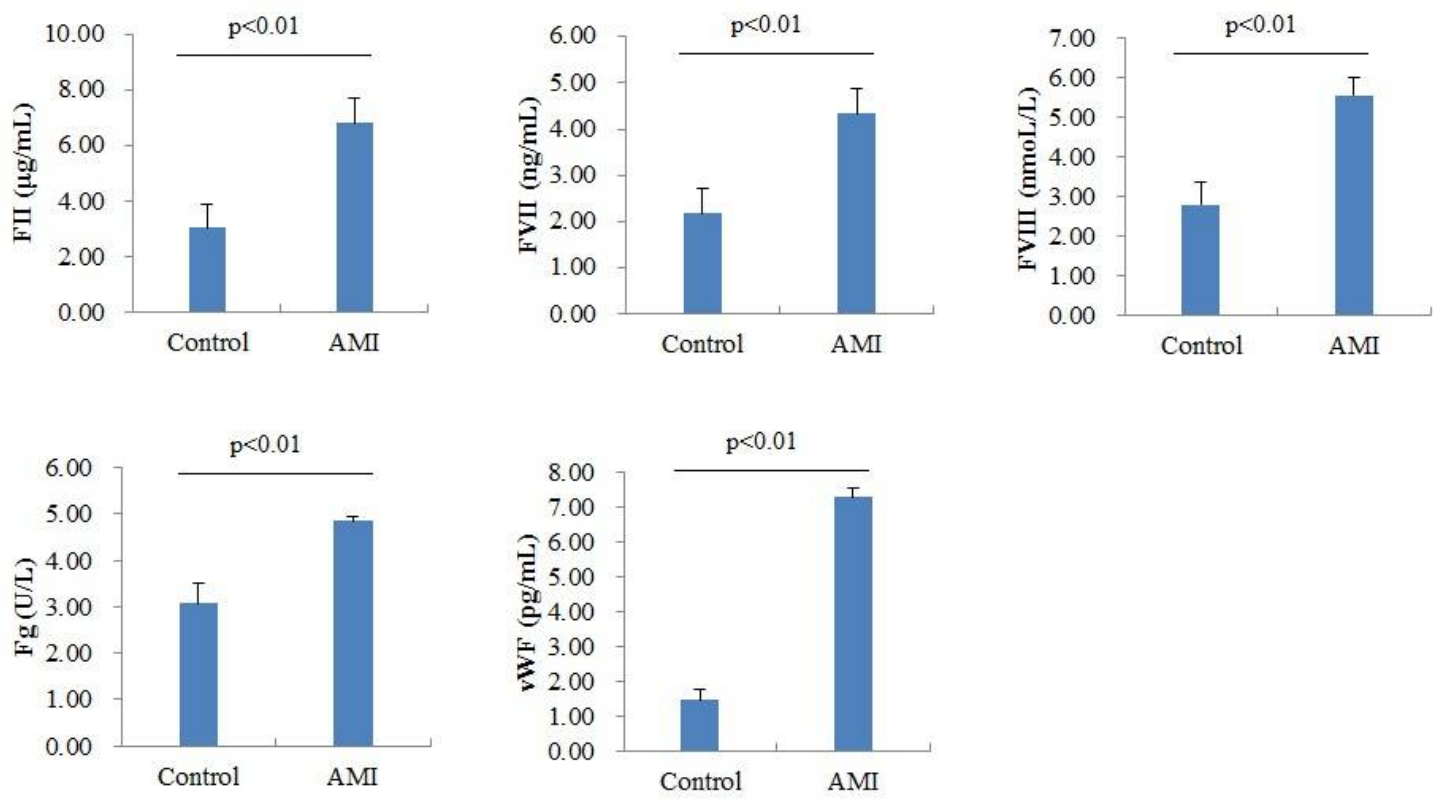

Figure 1: FII, FVII, FVIII, Fg and vWF levels in plasma. Data are expressed as mean \pm SD $(p<0.01)$, compared with control group

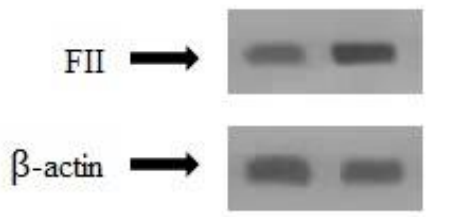

Control AMI

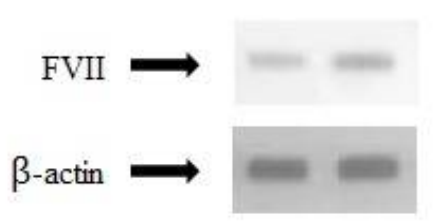

Control AMI

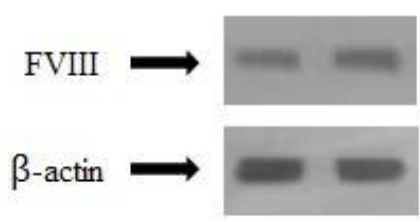

Control AMI

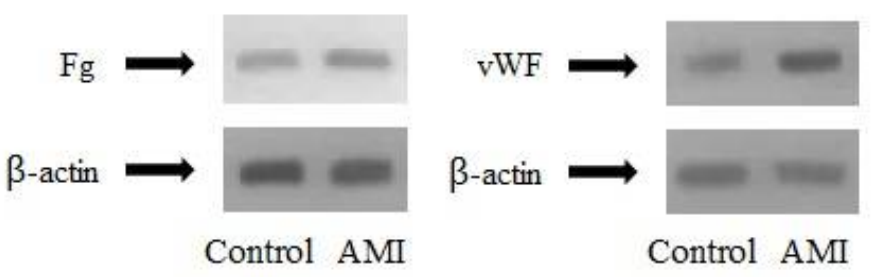

Figure 2: Protein expressions FII, FVII, FVIII, Fg and vWF in plasma of AMI patients 

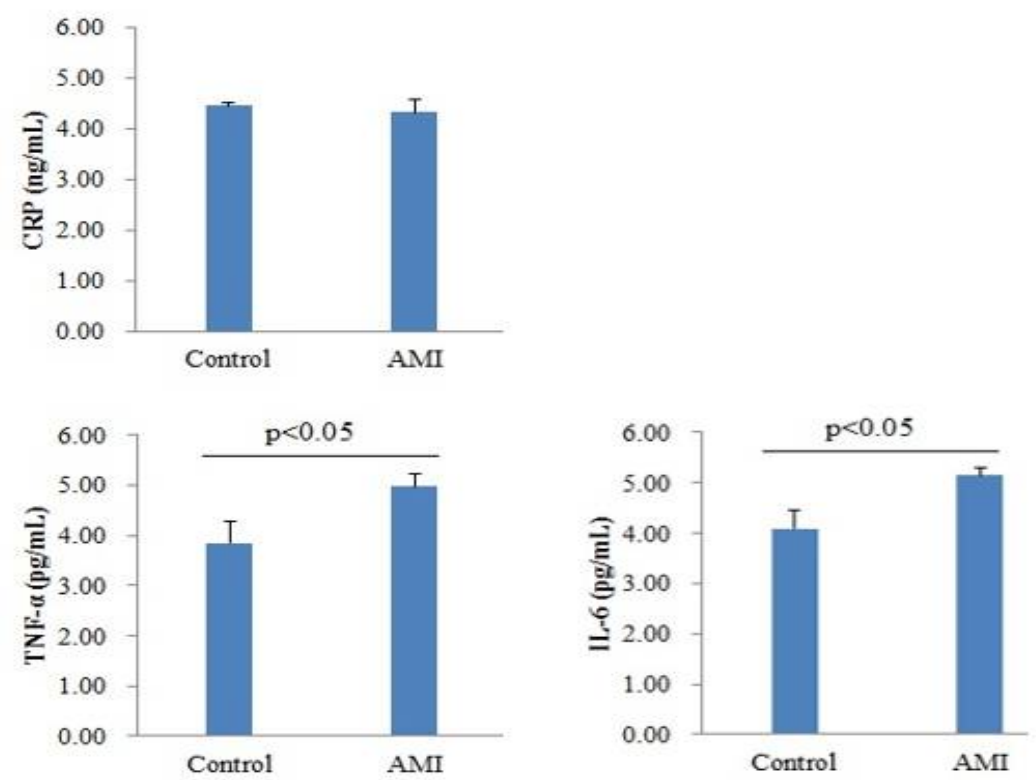

Figure 3: Plasma levels of CRP, TNF- $\alpha$ and IL-6. Data are expressed as mean \pm SD $(p<0.05)$, compared with control group

\section{DISCUSSION}

Recently, it had been reported that the AMI) is a frequent cause of death or severe permanent disability, and the age of AMI patients is becoming increasingly young $[12,13]$. Thus, the present study was designed to investigate the possible pathogenic mechanism of AMI in patients younger than 60 years related to coagulation factors and inflammatory cytokines.

AMI is associated with the coagulation and thrombotic occlusion of coronary vessels in the presence of unstable atheroma [14]. FII, FVII, FVIII, Fg and VWF are important coagulation factors in the blood coagulation process. FII (Prothrombin) plays a central role in the coagulation mechanism, and it can be activated to Flla (thrombin). Fg could then change into fibrin due to the activation of FIla [15]. FVII is the initiation factor of the exogenous coagulation pathway, and its abnormalities in the plasma may increase the risk of myocardial infarction and sudden death [16]. FVIII is involved in the second stage of the coagulation process, and it is also involved in the activation of coagulation factor $X$ (FX). In addition, vWF and FVII could form a complex to stabilize and protect the activity of FVIII [17]. Several literature sources have proved that these coagulation factors play important roles in the development of vascular disease and AMI [18-21]. Therefore, we evaluated the plasma levels of coagulation factors in AMI patients and control subjects. Our results indicate that the high levels of coagulation factors in plasma (FII, FVII, FVIII, Fg and vWF) were closely related to the development of $\mathrm{AMI}$ in patients younger than 60 years.

Increasing investigations have demonstrated that inflammation plays an important role in the pathogenesis of CHD. Inflammatory cytokines including CRP, TNF- $\alpha$ and IL- 6 mediate adverse cardiovascular events in patients with $\mathrm{CHD}$ and they are used as indices for diagnosing CHD $[22,23]$. In our present study, the levels of inflammatory cytokines, including CRP, TNF- $\alpha$ and IL-6, in plasma were determined. Our results showed that the levels of TNF- $\alpha$ and IL- 6 in AMI patients were higher than those control subjects, indicating that high levels of TNF- $\alpha$ and IL- 6 might be related to the development of $\mathrm{AMI}$ in patients younger than 60 years.

\section{CONCLUSION}

Findings from this study reveal that the pathogenesis of AMI in patients younger than 60 years might be closely related to the high levels of coagulation factors and inflammatory cytokines in the blood. In addition, the results of the present study would be beneficial for accurate diagnosis and effective treatment of AMI in clinic.

\section{REFERENCES}

1. Deniz Acar R, Bulut $M$, Ergün $S$, Yesin $M$, Alıcı $G$, Akçakoyun $M$. Effect of cardiac rehabilitation on left atrial functions in patients with acute myocardial infarction. Ann Phys Rehabil Med 2014; 57(2): 105-113. 
2. Di Dalmazi G, Vicennati V, Garelli S, Casadio E, Rinaldi E, Giampalma E, Mosconi C, Golfieri R, Paccapelo A, Pagotto U, Pasquali R. Cardiovascular events and mortality in patients with adrenal incidentalomas that are either non-secreting or associated with intermediate phenotype or subclinical Cushing's syndrome: a 15-year retrospective study. Lancet Diabetes Endocrinol 2014; 2(5): 396-405.

3. Sun CK, Zhen YY, Leu S, Tsai TH, Chang $L T$, Sheu JJ, Chen YL, Chua S, Chai HT, Lu HI, Chang HW, Lee FY, Yip HK. Direct implantation versus platelet-rich fibrinembedded adipose-derived mesenchymal stem cells in treating rat acute myocardial infarction. Int $\mathrm{J}$ Cardiol 2014; 173(3): 410-423.

4. Suresh R, Li X, Chiriac A, Goel K, Terzic A, Perez-Terzic $C$, Nelson TJ. Transcriptome from circulating cells suggests dysregulated pathways associated with longterm recurrent events following first-time myocardial infarction. J Mol Cell Cardiol 2014; 74: 13-21.

5. Vaccarino $L$, Vitale $S$, Caruso $M$, Palmeri $M$, Scola $L$, Bova M, Caruso C, Massenti MF, Vitale F, Novo S, Lio $D$, Forte GI. Myocardial infarction marker levels are influenced by prothrombin and tumor necrosis factor- $\alpha$ gene polymorphisms in young patients. Cytokine 2013; 61(1): 218-222.

6. Tan RS, Cook KR, Reilly WG. Myocardial Infarction and Stroke Risk in Young Healthy Men Treated with Injectable Testosterone. Int J Endocrinol 2015; 2015 : 970750.

7. Ferreira-González I. The epidemiology of coronary heart disease. Rev Esp Cardiol (Engl Ed) 2014; 67(2): 139144.

8. Batalla A, Alvarez R, Reguero JR, González P, Alvarez $V$, Cubero Gl, Cortina A, Coto E. Lack of association between polymorphisms of the coagulation factor VII and myocardial infarction in middle-aged Spanish men. Int J Cardiol 2001; 80(2-3): 209-212.

9. Jing $X$, Chen SS, Jing $W$, Tan $Q, Y u M X, T u J C$. Diagnostic potential of differentially expressed Homer1, $I L-1 \beta$, and TNF- $\alpha$ in coronary artery disease. Int $\mathrm{J} \mathrm{Mol}$ Sci 2014; 16(1): 535-546.

10. Fang L, Moore XL, Dart AM, Wang LM3. Systemic inflammatory response following acute myocardial infarction. J Geriatr Cardiol 2015; 12(3): 305-312.

11. WHO MONICA Project: MONICA Manual, revised ed., Geneva: Diseases Unit, WHO, 1990.

12. Yunyun $W$, Tong L, Yingwu L, Bojiang L, Yu W, Xiaomin $H$, Xin L, Wenjin P, Li J. Analysis of risk factors of STsegment elevation myocardial infarction in young patients. BMC Cardiovasc Disord 2014; 14: 179.

13. Karim MA, Majumder AA, Islam $K Q$, Alam MB, Paul ML, Islam MS, Chowdhury KN7, Islam SM. Risk factors and in-hospital outcome of acute ST segment elevation myocardial infarction in young Bangladeshi adults. BMC Cardiovasc Disord 2015; 15: 73.
14. Pinelli A, Trivulzio S, Rossoni G, Redaelli R, Brenna S. Factors involved in sudden coagulation observed in patients with acute myocardial infarction. In Vivo 2012; 26(6): 1021-1025.

15. Qi X, Ren W, De Stefano V, Fan D. Associations of coagulation factor $V$ Leiden and prothrombin G20210A mutations with Budd-Chiari syndrome and portal vein thrombosis: a systematic review and meta-analysis. Clin Gastroenterol Hepatol 2014; 12(11): 1801-1812.

16. Bozzini $C$, Girelli $D$, Bernardi $F$, Ferraresi $P$, Olivieri $O$, Pinotti M, Martinelli N, Manzato F, Friso S, Villa $G$, Pizzolo F, Beltrame F, Corrocher R. Influence of polymorphisms in the factor VII gene promoter on activated factor VII levels and on the risk of myocardial infarction in advanced coronary atherosclerosis. Thromb Haemost 2004; 92(3): 541-549.

17. Raquet E, Stockschlaeder M, Mueller-Cohrs J, Zollner S, Pragst I, Dickneite G. Utility of a high VWF: FVIII ratio in preventing FVIII accumulation: a study in VWF-deficient mice. Blood Coagul Fibrinolysis 2015; 26(5): 515-521.

18. Soejima $H$, Ogawa $H$, Suefuji $H$, Kaikita K, Takazoe $K$, Miyamoto S, Kajiwara I, Shimomura H, Sakamoto $T$, Yoshimura M, Nakamura S. Comparison of effects of losartan versus enalapril on fibrinolysis and coagulation in patients with acute myocardial infarction. Am J Cardiol 2001; 87(12): 1408-1411.

19. Itakura $H$, Sobel BE, Boothroyd D, Leung LL, Iribarren $C$, Go AS, Fortmann SP, Quertermous T, Hlatky MA. Do plasma biomarkers of coagulation and fibrinolysis differ between patients who have experienced an acute myocardial infarction versus stable exertional angina? Am Heart J 2007; 154(6): 1059-1064.

20. Holm J, Hillarp A, Erhardt L, Berntorp E. Changes in levels of factor VII and protein $S$ after acute myocardial infarction: effects of low-dose warfarin. Thromb Res 1999; 96(3): 205-212.

21. Valades-Mejía MG, Domínguez-López ML, AcevesChimal JL, Miranda AL, Majluf-Cruz A, Isordia-Salas I. Study of the polymorphism R353Q in the coagulation factor VII gene and the N700S in the thrombospondin-1 gene in young patients with acute myocardial infarction. Cir Cir 2014; 82(6): 595-606.

22. Song Z, Bai J, Zhang L, Sun $X$, Zhang $M$, Zheng $H$, Zhang J. Effects of telmisartan on inflammation and fibrosis after acute myocardial infarction in rats. Zhonghua Yi Xue Za Zhi 2014; 94(33): 2628-2633.

23. Moreira DM, da Silva RL, Vieira JL, Fattah T, Lueneberg $M E$, Gottschall CA. Role of vascular inflammation in coronary artery disease: potential of anti-inflammatory drugs in the prevention of atherothrombosis. Inflammation and anti-inflammatory drugs in coronary artery disease. Am J Cardiovasc Drugs 2015; 15(1): 111. 